\title{
High efficiency portable solar generator utilizing optimum solar panel orientation
}

\begin{abstract}
This paper presents optimized solar photovoltaic (PV) panels tilted angle software and portable solar generator for flood evacuation centre in Malaysia peninsular. Although Malaysia peninsular is located near the equatorial, there is still a need to optimize the solar PV panels tilted angle since the horizontally located solar PV panels receive less solar radiation especially in the early morning and late afternoon when the incident angle is not perpendicular to the sun. Therefore a tilted angle optimization is necessary to harvest maximum solar radiation. In this paper, the functionality of developed prototype is tested and the product design is shown in details. The testing and development is done in Universiti Putra Malaysia. The developed software is purposely to optimize the azimuth and altitude angles in which the calculation is from solar noon on designated date and time. It is an open loop system based on mathematical formula and it predicts the sun movement. Therefore sensors are not required to sense the sun location. The developed prototype structure is based on steel and able to hold $1 \mathrm{~kW}$ solar PV panels. It has stable base in which the battery bank, charge controller and inverter are embedded inside it. It is designed to be retractable so that it can be loaded in pick-up truck to be carried to flood evacuation centre. The tilted angle for altitude is optimized automatically by the motor when the angle value is key in to the processor. The azimuth angle can be adjusted manually since it may reduce the power consumptions. The proposed portable solar generator has been designed to generated 3.6 $\mathrm{kWh}$ per day based on $1 \mathrm{~kW}$ capacity. It can provide half of power requirement for scholl hall lighting which can power up 22 LED lights.
\end{abstract}

Keyword: Photovoltaic panels; Solar generator; Optimized tilted angle; Flood evacuation centre; Solar energy 